\title{
Direct and Interactive Effects of Brokerage Roles on Innovation in Clustered Firms
}

\author{
CRISTINA BOARI ${ }^{1}$, F. XAVIER MOLINA-MORALES ${ }^{2}$ AND LUIS MARTÍNEZ- \\ CHÁFER ${ }^{3}$
}

This Version: April 2015 (Preprint)

\begin{abstract}
Social network analysis has generated a great number of research findings in organizational and management literatures. Moreover, the so-called territorial clusters have been represented through the network metaphor. However, while scholars primarily examine the network structure and the internal heterogeneity, we have particularly analyzed the diverse types or roles of informational brokers which firms can develop. Furthermore, we posit that innovation generated by these firms is moderated by their own capabilities. Particularly, we analyze how innovation is affected by brokerage roles and the moderating effect of $R \& D$ in the Spanish ceramic tile cluster. Our results show that different brokerage roles played by clustered firms have different implications in terms of innovation. We found that some of them are positively associated to and others are not. Another relevant and related result refers to the interactive effect of brokerage roles and absorptive capacity some of them become more significant than others.
\end{abstract}

\section{Keywords}

Brokerage, Clusters, Innovation, Social Networks Analysis

\footnotetext{
${ }^{1}$ Università di Bologna, Department of business administration, Via Capo di Lucca 34, Bologna (Italy). Tel: +390512098075. Email: Cristina.boari@unibo.it

${ }^{2}$ Universtitat Jaume I, Department of Business Administration and Marketing, Av. Sos Baynat S/N, 12071, Castellón (Spain). Tel: +34964387117. Email: Molina@emp.uji.es

${ }^{3}$ Corresponding Author. Universtitat Jaume I, Department of Business Administration and Marketing, Av. Sos Baynat S/N, 12071, Castellón (Spain). Tel: +34964728543. Email: chafer@emp.uji.es ${ }^{4}$ Final journal version available here: http://onlinelibrary.wiley.com/doi/10.1111/grow.12170/full
} 


\section{Introduction}

Clusters have been recognized as an industrial form of organization that are able to impact on competitiveness, innovation and employment growth of firms, regions and countries (Porter 1990, 1998). Starting out from Marshall's (1925) seminal work, a growing body of literature has related knowledge diffusion among cluster firms to the innovation performance and competitiveness of the same firms and the cluster. The role played by intra-cluster relations in knowledge exchange is widely recognized in this literature (Saxenian 1991; Porter 1998; Maskell and Malmberg 1999; Breschi and Lissoni 2001; Cooke 2002; Sammarra and Biggiero 2008). Accordingly, geographic clusters are represented and analyzed through the network model in order to map and study both the actors involved and the interactions that take place among them (Branston et al. 2005; Boschma and Ter Wal 2007; Parrilli and Sacchetti 2008). This approach has attracted an overwhelming amount of attention and, accordingly, a body of literature has emerged that, within the network perspective, has devoted an increasing amount of attention to the role played by the individual actors, firms, and institutions involved in the transmission of knowledge among cluster firms (Lazerson and Lorenzoni 1999; Munari, Sobrero, and Malipiero 2012; Giuliani 2011; Boari and Lipparini 1999).

A rapidly developing part of this literature is focused on knowledge brokers, which are actors that transfer and combine existing ideas and knowledge among unconnected firms and institutions. For instance, gatekeepers (as a specific type of broker) are defined as actors that generate novelty by drawing on local and external knowledge in regions (Graf 2011; Graf and Kruger 2011; Morrison 2008). The potential advantages of cluster organizations as informational brokers were analyzed at length in 
Giuliani and Bell (2005), and the role played by local institutions as bridges connecting internal and external actors was studied in McEvily and Zaheer (1999) and MolinaMorales (2005).

Our study is grounded in this literature, which considers knowledge brokers as actors that are able to influence the distribution of knowledge in clusters and firms performance. Previous research has two major characteristics: it is mainly focused on brokers connecting local actors to the external environment (i.e., gatekeepers) and, accordingly, it limits its interest to the impact of the role of gatekeeper in terms of innovation. In the general network literature it is recognized that organizations in social structures, such as clusters, can play different brokerage roles, besides the gatekeeper role, depending on the position of the intermediated organizations and on the direction of knowledge flows (Gould and Fernandez 1989; Burt 2004). In contrast, research on clusters focuses only on gatekeepers and is interested in brokers accessing external knowledge (Giuliani and Bell 2005; Wink 2008; Morrison 2008), with a few recent exceptions for gatekeepers accessing both internal and external knowledge (Graf and Kruger 2011; Munari, Sobrero, and Malipiero 2012). On the one hand we have a very rich literature stressing the role of intra-cluster relations for knowledge exchange, while on the other hand the literature on knowledge brokers in clusters has mainly studied the implication on innovation for brokers connecting cluster firms to external sources of knowledge. Even though we recognize the great importance of these studies, we claim that nature and implications of different brokerage roles (besides that of gatekeeper) in terms of the innovation of cluster firms still needs to be evaluated, particularly with reference to intra-cluster diffusion of knowledge. Therefore, by focusing on the transmission of knowledge among cluster firms, our major research question is: how do different brokerage roles impact on firms innovation performance in clusters? 
We are also interested in determining the influence of a broker's characteristics on this relation in order to extend investigations on broker's attributes and their impact on innovation performance. (Giuliani and Bell 2005; Giuliani 2011; Spencer 2003; Morrison 2008; Graf 2011). In order to contribute we take a recent perspective on interfirm networks that studies how firms characteristics influence the benefits that firms can extract from their network position (Zaheer and Bell 2005; Lavie 2006; Shipilov 2009). As a contingency factor we focus on absorptive capacity, the internal factor that, by measuring firm capability in accessing knowledge, is considered tightly related to its innovation performance.

We base the analytical distinction of brokerage roles on the seminal work by Gould and Fernandez (1989), who argued that a number of qualitatively different mediation structures emerge when actors in transaction networks are differentiated into subgroups. They showed that these structures correspond to different brokerage roles. In other words, different roles can be found in the brokerage activities, depending on whether the actor belongs to one or another subgroup in the network. A firm that connects two others generates different opportunities with different goals for them. For example, in clusters, brokers could connect other firms located both inside and outside the cluster. Similarly brokers could connect firms belonging to different positions in the value system at the local level, thereby intermediating in vertical and horizontal relationships with other co-located firms. In our paper we explore how different brokerage activities (four different brokerage roles are analyzed), carried out at the local level, affect the innovative performance of clustered firms. Moreover, since the effects might be contingent on the focal firms' capabilities, we combine the effect of the brokerage activities with the firms' absorptive capacity to explore the existence of an interaction effect. 
To investigate our topic, we analyze the specific case of the Spanish ceramic tile cluster. This industrial cluster includes the production of ceramic floor and wall tiles, and other related and auxiliary activities. Previous cluster research identified this ceramic tile territorial agglomeration as a cluster (among others, Boix and Galletto 2006; Ybarra 1991) where knowledge creation is conditional on intra-cluster relations (Arikan and Schilling 2011). In order to compute the values of the brokerage activities, we collected data from a total of 166 questionnaires completed at the firm level.

Our paper contributes to the cluster literature by focusing on knowledge brokers as actors whose behavior can impact on the distribution of knowledge in clusters. We complement cluster literature investigating nature and implications of different brokerage roles with reference to intra-cluster diffusion of knowledge. We find that intermediating between various firms that are positioned differently in the local value system unevenly impacts on the broker's innovative performance. In particular we find evidences that the diversity of intermediated knowledge might be responsible of the higher innovative performance of the broker. Our second contribution refers to the moderating effect of the absorptive capacity of the broker on the network position effects. Prefiguring our results we collected evidences of a possible substitution effect between some brokerage roles and absorptive capacity. This result contributes to the debate on the role of firms' capabilities in cluster literature. Accordingly it also contributes to social network scholars' demand for further research that investigates how firm's characteristics would influence how a firm can benefit from its position in a network.

The paper is structured as follows. First, we present the theoretical framework, establish the research questions, and build the conceptual framework. We then explain 
the methodology applied in this research and the operationalization of the concepts, and finally results, conclusions, and their potential implications are discussed.

\section{Theoretical Framework and Hypotheses}

\section{Knowledge diffusion in clusters and innovation}

The role of knowledge diffusion in terms of innovation and competitiveness of clusters and cluster firms has been a key topic since the seminal works by Marshall (1925). From the beginning a great deal of interest has been devoted to the different relationships among cluster firms, which are considered key channels for information and knowledge diffusion. The perspective on network relationships has increasingly contributed to the studies on innovation in clusters. The cluster has been defined as a network within a production context inside a geographically defined area (Boschma and Ter Wal 2007; Branston et al. 2005; Parrilli and Sacchetti 2008). Contexts of geographical proximity such as industrial clusters (Porter 1998; Tallman et al. 2004) can be viewed as networks, since many different actors are involved, including final product firms, suppliers, customers, service providers, local institutions and policy agents, and they interact in a differentiated set of relationships. The establishment of linkages between firms that are co-located in a local area is critical for the existence of localized knowledge flows and transfers (Li, Veliyath, and Tan 2013; Rosenkopf and Almeida 2003).

While some previous studies recognized a homogeneous distribution of knowledge among cluster firms (Brusco 1982; Piore and Sabel 1984), more recent studies are more interested in understanding the sources of uneven and asymmetric distribution of knowledge in clusters. A number of authors agree that not all firms in a 
cluster are involved in local networks (Bathelt, Malmberg, and Maskell 2004; Giuliani 2007). In fact, knowledge access is usually restricted to subgroups within the network (Boschma and Ter Wal 2007; Giuliani and Bell 2005; Lissoni 2001; Malipiero, Munari, and Sobrero 2005). As a result it can be stated that knowledge spreads unevenly among members of a local agglomeration of economic activities (Giuliani and Bell 2005). This unevenness is caused by the internal heterogeneity of the cluster's firms, and also generates diverse consequences for the local networks (Camuffo 2003).

Discussing the heterogeneity of the internal network structures has represented a step forward in the research on innovation in clusters. Giuliani (2007), for instance, found that the knowledge associated with innovation is distributed in a selective, uneven manner. In the same vein, the findings of Morrison and Rabellotti (2009) supported the idea that knowledge flows are restricted to a tightly closed group of local producers that are significantly distinct with respect to the rest of the members of the cluster. Moreover, Giuliani and Bell (2005) found strong support to the idea that firms can transfer knowledge asymmetrically, that is, knowledge exchange can occur even when reciprocity is not happening (Bouty 2000).

Besides the interest in network relations among cluster firms, this literature also recognizes the key role of focal firms, whose characteristics and relations are considered to be responsible for the heterogeneous distribution of knowledge in clusters. Focal firms (also called leading firms, anchor tenants, strategic centers, brokers and gatekeepers) are not only critical due to their higher ability to coordinate and guide other cluster firms to innovation, but also play a key role in transferring relevant knowledge among firms located both within and outside the cluster (Boari and Lipparini 1999; Lazerson and Lorenzoni 1999). Looking at the development of this approach, there is obviously an increasing interest in the relationship of focal firms with other 
firms and institutions located outside the cluster. This more recent literature shares an interest in the access to external knowledge and therefore focuses mainly on gatekeepers, defined as a specific type of broker that, by acting as bridges connecting external and local organizations, transfer external knowledge to cluster firms (Morrison 2008; Giuliani 2011; Wink 2008; Graf 2011), eventually combining it with local knowledge (Graf and Kruger 2011; Munari, Sobrero, and Malipiero 2012).

By focusing on the role of focal actors and their network relations in knowledge diffusion and innovation in clusters, we intend to investigate the role of different types of brokers (besides gatekeepers), as suggested by the network literature (Gould and Fernandez 1989). We recognize that heterogeneous distribution of knowledge could be ascribed to how knowledge is accessed and transferred by knowledge brokers with reference both to external and internal knowledge and this could have a different impact on the innovative performance of cluster firms. Moreover, by concentrating on intracluster relations, our aim is to make a direct contribution to the original stream of research on innovation in clusters, which looked at knowledge exchanges with rivals, suppliers and other firms involved in related industries at the local level (Porter 1990). With this theoretical framework in mind, we dedicate the next section to presenting the theory about knowledge brokers and to formulating our hypotheses on the relationship between brokerage roles and innovation, and about the influence of the broker's characteristics on this relationship.

\section{Brokerage activities and innovation}

Social network theories describe the benefits of being a bridge between other actors in the network. Burt (1992) argued that to discover new opportunities and ideas it is not so much the strength or weakness of a tie that determines its information potential, but rather whether an actor's contacts are connected to each other or not, that 
is, if a structural hole exists between a focal actor's contacts. The structural holes argument defines social capital in terms of the advantages, in terms of information and control, of being a broker in relations between people who are otherwise unconnected in the social structure. The structural hole is an opportunity to broker the flow of information between people and control other actors in the network. The information benefits of being a broker can be defined in terms of better access to external information, better timing in this access, and a better referral for the actor (Burt 1992).

Specifically, Marsden (1982) defined brokerage as a process by which intermediary actors facilitate transactions between other actors lacking access to or trust in one another. In research on innovation management the concept of knowledge broker is identified as the role played by particular actors (individuals or organizations) that are able to connect different communities, thus generating flows of knowledge between them (Hargadon 1998; Boari and Riboldazzi 2014).

In the context of geographical clusters it could be suggested that firms acting as connectors between subclusters maintain bridging ties. For instance, McEvily and Zaheer (1999) theorized that bridging ties connect a focal firm to sources of information and opportunities that are not available from other network contacts. They proposed that heterogeneity in firms' networks of bridging ties are important sources of differences in firms' competitive capabilities. Similarly, Molina-Morales (2005) analyzed the role played by the local institutions in clusters as intermediary or broker actors that connect external and internal networks.

An increase in the innovative performance of a firm could be a benefit of its brokerage activities. Becker (1970) argued that actors positioned in a preferred location in the network receive innovation-related information that other firms might miss. On the other hand, network scholars often treat innovativeness as a function of network 
position. Galunic and Rodan (1998) further built on the work of Hargadon and Sutton (1997), who had found that a firm at the confluence of several industries was able to broker the knowledge derived from the multiple industries to create new business concepts. Recently, the importance of knowledge brokers in generating innovation has been widely evidenced (Uzzi and Spiro 2005; Boari and Riboldazzi 2014).

In the literature about clusters the relationship between brokerage activities and innovation has been mainly focused on gatekeepers accessing external sources of knowledge (Morrison 2008; Giuliani 2011; Wink 2008; Graf 2011), eventually combining it with local knowledge (Graf and Kruger 2011; Munari, Sobrero, and Malipiero 2012). It has also been shown that the intensity of a gatekeeper activity may have an impact on innovation performance (Graf and Kruger 2011). Accordingly, we start by arguing that any brokerage activity exerts positive effects on firm innovativeness. Thus, we hypothesize:

H1: The level of intensity in the brokerage roles played by cluster firms will be positively associated to their innovative performance.

Previously, brokerage activities of actors were discussed without distinguishing among them, that is, actors were considered as a single uniform group. However, actors in a network can be grouped in different manners according to their activities or interests, thereby changing the nature and implications of the knowledge exchanges. In other words, it makes sense to partition the full group into a set of mutually exclusive (non-overlapping) classes or subgroups of actors (Gould and Fernandez 1989). According to these authors, we can identify four structurally distinct types of brokers ${ }^{1}$ (or, equivalently, four types of brokerage relations) that follow from a partitioning of 
actors into non-overlapping subgroups (Figure 1): (1) Coordinator. This type occurs when all three actors belong to the same group, so that the brokerage relation is completely internal to the group. It is called coordinator because this kind of exchange involves the services of an agent who is a member of the same group as the principals. (2) Representative. This role is created when one or more members of a subgroup delegate one of their own to communicate information to, or negotiate exchanges with, outsiders. (3) Gatekeeper occurs when an actor selectively grants outsiders access to members of his or her own group. (4) Liaison. This is a type that is another form of broker, but in this case the broker is an outsider with respect to both the initiator of the brokerage relation and the receiver of the relation. This actor's role is to link distinct groups without having prior allegiance to either.

\section{INSERT FIGURE 1 ABOUT HERE}

Each type of broker should be treated in a different manner depending on the groups of actors they are connected with. In this way, distinct brokerage roles can be clearly differentiated to accommodate contexts and goals, consistently with previous research (Graf and Kruger 2011).

We claim that it could be useful to distinguish and compare the effects of the different types of brokerage roles on the innovation of the clustered firms. In geographic clusters, different productive activities of the whole value system can be identified as classes or subgroups of actors. Brokers can connect groups that are located in different places in the value system of the cluster. Different triads, formed by a firm acting as a bridge between two others, create different contexts with different goals and accessed information for the broker. As a consequence we are able to distinguish two categories of ties that the broker creates with intermediary partners, namely, horizontal ties with 
actors belonging to the same position in the value system, and vertical ties with actors belonging to different positions (i.e., the customer-supplier relationship).

There is a different theoretical reasoning behind horizontal and vertical ties and, in consequence, the implications for innovation of brokerage roles might also be different. In the case of the coordinator, one firm connects only with firms in the same position in the value system, that is, with rival firms. In the role of the representative, the firm receives knowledge from another firm in the same position, but it acts as the source for a firm in another position. In the liaison role, a firm receives and transfers knowledge to firms located in different positions, that is, the broker has vertical ties with intermediated firms, which are therefore complementary to each other. Finally, gatekeeper combines both categories of ties in different ways, receiving from a different group but acting as a source for firms sharing the same position. To sum up, concerning the source of the knowledge that actors receive, liaison and gatekeeper access knowledge from vertical ties while coordinator and representative access knowledge from horizontal ties.

The literature on interfirm relationships is rich in evidence on the role of vertical relationships with suppliers and customers on competitiveness and innovation capability. Relations and knowledge acquisition between firm and customer favor the potential for new innovative combinations and for reducing phases of the innovation process (Von Hippel 1977; Yli-Renko, Autio, and Sapienza 2001). Japanese manufacturers improve product-development coordination by interacting heavily with their suppliers (Dyer and Nobeoka 2000). The capability to interact with suppliers accelerates the firm's access to and transfer of knowledge with relevant effects on company growth and innovativeness (Lorenzoni and Lipparini 1999). 
The impact of horizontal relations on innovation has received less attention from researchers. There is evidence that, if present, horizontal ties are less important than vertical ones (Tomlinson 2010). As regards clusters, vertical local knowledge relations are more widespread and considered more important as far as the transfer of technical knowledge is concerned. This could be due to the fact that the existing firm-supplier relationships within the cluster may automatically induce some flows of technical knowledge and that the fear of unintended imitation by competitors, which usually characterizes horizontal ties, is lacking in the case of vertical relationships (Boschma and Ter Wal 2007). By adopting this perspective based on the vertical and horizontal sources of information, we could expect a higher innovative performance in brokers playing a liaison or a gatekeeper role than in those playing a coordination or representative role.

We might also adopt a different perspective that, while not subverting the previous one, is more focused on the diversity of intermediated knowledge. Burt (2004) claims that, while addressing brokerage roles, sources of knowledge might not be the focal question. Brokers create value in different ways: by identifying different interests and difficulties, by transferring best practices, by identifying analogies and by combining knowledge originated in different groups. Empirical research shows that what matters for innovation is how diverse and even contradictory the intermediated information and its possible interpretation are. It has been said that "Creativity is an import-export business" (Burt 2004), due to the fact that the same information can be valuable in one group and useless in another.

Based on this reasoning, we are able to predict a different effect of distinct brokerage roles on the innovation of the firms in the industrial cluster. We expect brokers playing a liaison role, by intermediating between different groups involved in 
different technologies/markets, to be the ones that are most able to benefit from diversity and possible contradictions. In contrast, by intermediating between rival firms, coordinators have the lowest chance of developing innovation. This is based on the possible redundancy of the information that is accessed, which is particularly predictable in a cluster. This is even reinforced by the need for the firm to tightly control the knowledge flow in relationships involving competitors. We expect gatekeepers and representatives to be somehow in-between liaisons and coordinators. By intermediating between firms of the same group (competitors) and other groups (suppliers), the level of diversity of information that they intermediate has an impact at an intermediate level of innovative performance. Accordingly, our hypothesis is as follows:

H2- Different brokerage roles played by cluster firms have different impacts on their innovative performance. In particular, cluster firms playing a liaison role have the highest innovative performance, while cluster firms playing a coordination role have the lowest.

\section{Interactive effect of absorptive capacity}

While connections with external knowledge sources are clearly critical to innovativeness, exclusive attention to the network structure as an antecedent of innovativeness obscures the role of the many intrinsic organizational characteristics that also influence a firm's innovative performance. Network position is not enough - you need the capabilities to take advantage of the position. Previous research suggests strong support for the thesis that firm-specific factors enhance innovative performance. In fact, 
we can claim that network structure influences firm outcomes, but these effects may be contingent on the focal firm's capabilities (Zaheer and Bell 2005).

As argued by the Resource-Based View (RBV) (e.g., Barney 1991), organizational capabilities, like resources, are likely to have significant impacts on a firm's outcomes. In consequence, a focal firm's capabilities are likely to be an important source of variance in firm performance. As Adler and Kwon (2002) pointed out, firm-specific capacities can act as complementary resources. More specifically, the firm may possess internal characteristics (such as a strong $R \& D$ team, internal organizational structures, and organizational culture) that make it more innovative than its competitors. Particularly, innovativeness is closely tied to R\&D effort as an indicator of absorptive capacity, which is defined as the capability of the firm to utilize and exploit knowledge obtained from external sources (Cohen and Levinthal 1990, 1994). Previous studies on gatekeepers in regional networks showed that a broker's attributes have a significant impact on innovation performance (Giuliani and Bell 2005; Spencer 2003). It was demonstrated that the level of absorptive capacity has a positive influence on the probability of being a gatekeeper (Giuliani and Bell 2005; Giuliani 2011; Morrison 2008; Graf 2011).

According with other researchers (Zaheer and Bell 2005; Lavie 2006; Shipilov 2009) we take a step forward and argue that a firm's capacities interact with its network position and may have an impact on the firm's innovation. We consider firm absorptive capacity as a contingency factor positively moderating the relationship between firm's network position and its innovative performance. That is, firms with a relatively higher $\mathrm{R} \& \mathrm{D}$ effort are better able to benefit from their brokerage position in terms of innovation. 
Following our reasoning, we set a hypothesis that proposes that focal firm absorptive capability affects the exploitation of the resources accessed through brokerage activities. Thus, as a baseline hypothesis we state:

H3: Absorptive capacity positively moderates the effect of brokerage roles played by cluster firms on their innovative performance.

\section{Empirical Setting}

The context of the research

The empirical study is contextualized in the Spanish ceramic tile cluster. The Spanish cluster is situated in the province of Castellón and more specifically in the counties of la Plana Alta, la Plana Baixa and L'Alcalaten. Over 90 percent of the total Spanish production is manufactured in this area, which has a radius of only 20 kilometers. This industry includes the production of ceramic floor and wall tiles, and other related and ancillary activities such as the production of decorative pieces, chemical additives, ceramic glazes and frits, machinery and equipment, and atomized clay suppliers, amongst others. Together with firms there are also a number of local institutions and supporting organizations which offer support and services for the whole cluster. These institutions include the local university, research institutes, policy agents, trade associations, and others. The ceramic tile is still an expanding industry distributed around the world, mostly in cluster-type geographical concentrations, and Spain is one of the world's leading producers together with countries like China, Italy or Brazil.

The Spanish ceramic tile industrial cluster is characterized by small-sized firms, specialization, and important product and technological overlaps. Known for being a 
traditional industry, it can be considered a very dynamic cluster as regards technological advances, which are focused particularly on process and product improvements. There is also an intensive use of knowledge transmission mechanisms, such as the creation of firms, human resource mobility and informal channels of communication and, finally, a specific cluster technology and common perception of markets (Molina-Morales 2002). The prominent role of the suppliers' linkages with the ceramic tile producers is well known in the Castellon cluster (Hervas-Oliver 2004) and constitutes a core advantage at the cluster level. Particularly, innovation in this cluster is basically of the exploitativetype, since the cluster is in a mature stage of development. The strong ties and dense structure of internal relationships favor this model of innovation. There are knowledge spillovers inside the cluster, where suppliers work with multiple customers, thus allowing the diffusion of information and knowledge resources under the conditions of the cluster internal market.

Previous research has already identified and analyzed the Spanish ceramic tile as a cluster (Ybarra 1991; Giner and Santa María 2002; Boix and Galletto 2006). Arikan and Schilling (2011) recognized in the Spanish ceramic tile cluster the traits of their cluster archetype with high coordination and low centralization. In this archetype there is a high need for coordination due to technological complexity, which brings firms to disintegrate and specialize in different activities and engage in a large set of network relationships with other specialized firms to deliver the final products. Moreover, even if some firms can grow large, no firm is large enough to control the cluster. Firms belonging to this archetype not only enjoy the traditional externalities but can also benefit from better rates of knowledge creation that "are entirely conditional upon the nature of intra-district relationships" (Arikan and Schilling 2011). In short, in the Spanish ceramic tile industrial cluster in Castellon, firms need to coordinate intensively 
to create knowledge, which makes knowledge brokers and network relations key drivers of knowledge flows.

\section{Data collection}

This study is based on data collected from the Spanish ceramic tile cluster at the firm level using questionnaires and interviews carried out with the firms' managers and engineers in charge of $R \& D$ activities or the production process. Since the questions included in the questionnaire concern diverse aspects of the relationships involving technological and informational exchanges, and given the characteristics of the companies (most of them SMEs), we consider this profile the most adequate to answer our questionnaire (see Table 1). The survey was carried out between February 2011 and July 2011 and was aimed at companies involved in the different cluster activities, that is, ceramic floor and wall tiles, decorative pieces, chemical additives, glazes and frits, machinery and equipment, and atomized clay producers. The survey was targeted toward a universe of 238 cluster companies, although we finally collected a total of 166 completed questionnaires, accounting for $69.5 \%$ of the total. This response rate is similar to what is often obtained by network researchers, according to Stork and Richards (1992). To avoid problems of representativeness, we ended up restricting our attention to the subset of individuals for whom network information is complete.

\section{INSERT TABLE 1 ABOUT HERE}

In order to observe the brokerage activities, we divided cases into a set of mutually exclusive (non-overlapping) classes or subgroups. This implies that communication or resource flows within groups should, in general, be distinguished from flows between groups. In the case of the geographic clusters, different productive activities of the whole value chain can be identified as classes or subgroups of actors. 
In order to make the partition of the cluster system into a set of mutually exclusive classes or subgroups, we considered the different productive activities of the whole value chain in the cluster. Table 2 reports how companies were distributed into the productive activities. Distinctions among these activities are relevant for our analysis, since we considered classes or subgroups of actors in order to trace the brokerage relations of all the firms in our sample.

\section{INSERT TABLE 2 ABOUT HERE}

\section{The network of technical knowledge}

In order to compute the values of the brokerage activities, we created questions that run in both directions, that is to say, questions that asked respondents about the destination of their information and the source of the information they had access to. The relational data were collected through a roster recall method: each firm was presented with a list (roster) of other firms in the cluster and also blank spaces to name firms not included on the roster. They were asked the following questions: (1) as a receiver, Question 1: if your company needs to solve some technical problem or receive some help in this area, which of the firms and organizations from the roster has it had some kind of relationship with in the last three years? As a source, Question 2: which of the firms mentioned in the roster have benefited from your help about diverse aspects of technical knowledge during the last three years? Technical information includes aspects such as: production techniques, product applications, chemical additives, raw materials, characteristics and performance of machinery and technology, glaze applications, new technologies, and so forth.

After gathering all the information we found out the different points of view held by the interviewees. These differences can be appreciated in the recognition of some of the relationships and also in their intensity. To solve this issue we took the receivers' 
opinion as the prevailing one in cases of conflict, given the fact that the actor who receives the help is in a better position to evaluate its importance. The final matrices were built accordingly.

\section{Analysis techniques}

To conduct the research reported in this paper Social Network Analysis (SNA) was used. According to Hanneman and Riddle (2001), SNA is the mapping and measuring of relationships and flows among people, groups, organizations, or other information/knowledge-processing entities. This technique has been suggested by several authors (Borgatti et al. 2009; Boschma and Ter Wal 2007; Graf 2011) as suitable for the study of business networks, especially in clusters (Boschma and Ter Wal 2007; Giuliani 2007; Morrison 2008; Morrison and Rabellotti 2009). In our case, SNA was utilized to compute the brokerage effects in the technical knowledge network. To do so, we used UCINET software v.6 (Borgatti, Everett, and Freeman 2002). In particular we built a network matrix $(166 \times 166)$ in which we gathered the corresponding relationships between companies in the surveyed cluster.

On the other hand, in order to test the hypotheses, we ran a hierarchical regression analysis, since an interactive effect exists if and only if the interaction term gives a significant contribution on the direct effects model (Cohen et al. 1983). The levels of significance of the regression coefficients should be examined together. To assess how interactive variables affect the dependent variable, we usually have to include the values of the interactive effects in the regression equation and represent these values against those obtained for the dependent variable. These representations show the effect of a variable, given the combination of values for the other variables. Before proceeding with this hierarchical regression, we controlled for multicollinearity problems between the variables involved (see Table 3). 


\section{Dependent variable}

Innovative performance

The technological knowledge of the network was matched with the selected technological items of the dependent variable. We focused on product and process items that have a technical profile. To capture the innovation results we built an indicator composed of a total of five items that ask respondents about product and process innovations (see Annex 1). These five items were introduced in a factorial calculation that gave us an overall value for each actor's innovation performance (Cronbach's alpha $=0.780 ; \mathrm{KMO}=0.784)$.

\section{Independent variables}

\section{Brokerage Roles}

As independent variables, four different broker roles were chosen: Coordinator, Gatekeeper, Representative, and Liaison, and for the analysis the G\&F Brokerage Roles algorithm in UCINET was used (Borgatti, Everett, and Freeman 2002). This allowed us to obtain measures to evaluate the degree to which actors in the network behave like each of the broker roles. Thus, an actor $j$ is considered to be a broker (intermediary) between actors $i$ and $k$ if and only if the condition $i j k$ is accomplished applying the terms and characteristics which describe each type of broker role.

We obtained the indicator of the number of times that $j$ appears in one triad relationship for each role, a measure that we call total individual, or unweighted, brokerage. This approach gives an unweighted indicator of the total number of intermediations that an actor possesses in the network. To know whether brokerage values in the network are relevant or not, we compared them with those that would be randomly obtained in a network with the same actors and subgroups as those in the 
network under study. Using UCINET (Borgatti, Everett, and Freeman 2002), the measure of the relative brokerage was calculated by dividing the value in our network by the estimated one obtained in the random network. In other words, the relative brokerage gives us an idea of the importance of the brokerage values in each case. Thus, the relative brokerages of each role were the independent variables in our regression.

\section{Absorptive capacity}

The absorptive capacity through the R\&D effort was captured by computing R\&D expenditure as a percentage of total revenue. This approach has already been used in some previous research carried out by authors like Cohen and Levinthal (1990) or Tsai (2001).

\section{Control variables}

External openness

The questionnaire asked about the firms' acquisition of knowledge from sources outside the cluster, at both the national and international levels, in accordance with more recent studies (Bathelt, Malmberg, and Maskell 2004; Owen-Smith and Powell 2004). Specifically, respondents were shown a roster of possible extra-cluster sources of knowledge (universities, technological centers, other groups of firms, customers, suppliers, consultants, public research centers, research, etc.) and asked to name those that had contributed to the technical enhancement of firms.

The indicator is computed on two alternative bases. On the one hand, Dichotomous reflects the presence/absence of linkages with cluster external actors, while the Weighted alternative analyzes the importance given to each linkage by the knowledge-user (a range of 0-3). We consider that those actors that received knowledge resources from outside the cluster are likely to be in a better condition to feed it to the 
rest of the actors inside the cluster. More specifically, the following question was formulated, Question 3: among these sources of knowledge, could you indicate or mark those that have transferred technical knowledge or have collaborated with your firm? Please indicate the geographical location of the source of knowledge in each case by marking the identified firms on one of the two possible values: $1=$ inside the cluster or $2=$ outside the cluster. To obtain the variable External Openness, we only have to compute the simple sum of the external linkages weighted by the value of the scale capturing the importance given to each linkage.

Size

Size was operationalized by running a factor analysis of the following items: (1) Number of employees, (2) total assets, and (3) total revenues for the last year. According to Acs and Audretsch (1991) or Mowery et al. (1996), size and innovation are associated. It is assumed that larger organizations have more capacity to acquire and generate knowledge resources and consequently are more likely to show a greater capacity for innovation (Tsai and Ghoshal 1998).

Age of the R\&D Department

This variable represents the number of years that the $R \& D$ department is performing its function in the firm. We obtained this information by directly asking the companies during the fieldwork. We introduce this variable in the model assuming that having an experienced $\mathrm{R} \& \mathrm{D}$ department is likely to provide better innovation performance in the firm (Engelen and Brettel 2012).

Age of the firm

This has been also a classical control variable when innovation is involved. In fact the research body on innovation highlights the importance of the firm's age as a 
control variable (Autio, Sapienza, and Almeida 2000). We calculate the age by obtaining the year of foundation through secondary resources like the SABI database ${ }^{2}$. Then we obtain the number of years that the company has been active till the year when the fieldwork is performed.

Table 3 shows the correlation matrix with the descriptive statistics, which thereby allows us to discard problems of multicollinearity.

\section{INSERT TABLE 3 ABOUT HERE}

\section{Results}

In order to test individual and interactive effects between brokerage activities and absorptive capacity (Table 4), we introduced the groups of independent variables step by step (Hair et al. 2006). In the first model we included the control variables, size, external openness, age of the $\mathrm{R} \& \mathrm{D}$ department and age of the firm. In model 2, we introduced the variables corresponding to the simple or direct effect of the brokerage activities, and in model 3 we added the absorptive capacity variable. Finally, in model 4, we introduced the interactive effects.

\section{INSERT TABLE 4 ABOUT HERE}

With respect to the specific variables, in model 4 two brokerage roles were significant (coordinator and liaison), both of them with positive effects. Therefore, Hypothesis 1 was only partially supported. On the other hand, brokerage roles vary in terms of which groups they connect and, consequently, in how they affect innovation, thus is partially supported Hypothesis 2. In fact, if we analyze the coefficients of the different roles, we can observe how the Liaison role, which involves three groups in the exchange of knowledge, has the highest positive effect, followed by the coordinator, which involves actors belonging to the same subgroup. The Gatekeeper and 
Representative roles have positive and negative effects respectively, although neither of them is significant. Furthermore, External openness and the age of the R\&D department exert a positive and significant effect on innovative performance. Overall, the positive impact of external openness has been supported in previous studies by authors like Bathelt et al. (2004) and Giuliani (2013). The same happens with the results obtained regarding the $\mathrm{R} \& \mathrm{D}$ department that has also been supported previously in the literature (See Engelen and Brettel 2012). On the other side, the age of the firm is not significant in the final model.

Finally, the variable that represents absorptive capacity also has a positive and significant effect on innovation. This result is aligned with what is argued by the RBV (e.g. Barney 1991), since an internal capability such us R\&D effort can potentially make a firm more innovative than its competitors.

Regarding size, the lack of significance cannot be considered an unexpected result since it is in agreement with other similar studies on clusters. Although the importance of size in these contexts is controversial, Russo (1985) argued that size and scale are not as relevant within a cluster as in other contexts, and therefore economies of scale are not significant in these frameworks because there is an intense division of labor among firms.

Regarding Hypothesis 3, the explanatory capacity of the general model is quite relevant, with an adjusted $R^{2}$ of 0.343 . Moreover, the increase in $R^{2}$ from model 3 to model 4 is significant, thus supporting the existence of an interactive effect. This interactive effect can be seen in the liaison role. This role has a significant negative interactive coefficient in the regression representing the unit change in the effect of this role when the absorption capacity varies. To appreciate this better, our study includes a graphical representation of these significant relationships (Figure 2). The Y-axis 
represents the dependent variable (innovative performance) and the $\mathrm{X}$-axis shows liaison activity for high and low levels of absorptive capacities. The effect of higher absorptive capacity on the brokerage role can be seen as the slope of the line decreases. This can be appreciated in the dotted line that shows what happens for high absorptive capacity values. These results are also in line with Hypothesis 2, as the role that involves more groups (liaison) still has the best influence on innovation.

\section{INSERT FIGURE 2 ABOUT HERE}

\section{Discussion and Conclusion}

In order to contribute to the literature that considers knowledge brokers as actors capable of exerting an influence upon the uneven distribution of knowledge in clusters, we analyzed the impact of different brokerage roles on the performance of clustered firms. This paper proposes an analytical distinction between different brokerage roles performed between distinctive subgroups or sub-networks that are connected by brokers. Based on the typology put forward by Gould and Fernandez (1989), we explored how different types of brokerage activities affect the innovative performance of clustered firms.

Our results show that different brokerage roles played by clustered firms have different implications in terms of innovation. We found that some of them are positively associated to and others are not. The positive relation between the liaison role and innovative performance, regardless of the level of the broker's absorptive capacity, suggests the opportunity for a broker to benefit from intermediating between different subgroups (for example, collecting information from a supplier of special components and transferring information to a supplier of machinery), taking advantage of diverse 
and even contradictory knowledge. The same relation exists between the coordinator role and innovative performance, but the positive effect is lower, then supporting the idea that the diversity of intermediated knowledge much better fosters innovation.

We did not find significant evidences of a positive relationship between other brokerage roles, such as gatekeeper and representative, and innovative performance. This results is difficult to explain only accordingly with the perspective we adopted to rise our hypothesis. As a matter of fact the diversity of intermediated knowledge per se does not support the negative, even if not significant, impact of the representative role on innovative performance. In general terms our results concerning the uneven impact of brokerage roles on innovation are consistent with what other authors suggested in studies at the intra-organizational and inter-organizational levels. Some authors (Shi, Markoczy, and Dess 2009; Obstfeld 2005) raised doubts as to whether brokers benefit from their position in any circumstances. Different brokerage roles might not only involve different relationships and information flows around the broker, but could also determine different advantages for the brokers, depending on their internal characteristics (Shipilov 2009). Moreover, sometimes acting as a brokers is not a strategic decision but the result of a more complex reciprocal behavior, therefor contingent on factors that are related to the nature of the relationship. Accordingly, clustered firms in each brokerage role can be expected to be constrained or facilitated within specific performance contexts and strategic objectives with heterogeneous performance implications. This reasoning further align us with the growing awareness among scholars on the need to appreciate specific internal contingencies (such as absorptive capacity, bargaining power, and protection against non-cooperation of partner) and relation specific characteristics (such as duration and strength of ties and 
proximity between actors) in the relationship between the actor's structural position and its performance (Shipilov 2009; Whittington, Owen-Smith, and Powell 2009).

Another relevant and related conclusion refers to the interactive effect of brokerage roles and absorptive capacity. While an interactive effect for the roles of coordinator, gatekeeper and representative could not be found; we did find that absorptive capacity moderates the effect of the liaison role on the firm's innovative performance. Actors with high absorptive capacities in combination with liaison activities are able to reach higher levels of innovative performance. In contrast, firms with lower absorptive capacity seem to benefit comparatively more from their liaison role, in terms of innovation, than firms with higher absorptive capacity. This result was somewhat unexpected and it is worthy to discuss in more detail.

First, it could be explained in terms of a possible substitution effect between some brokerage roles and $R \& D$ investments, the measure we used for absorptive capacity. By providing access to diversified knowledge, some brokerage activities might be partial substitutes for internal investments on absorptive capacity. For example they could accelerate the learning process, compensating low levels of internal investments in $R \& D$. This interpretation is in line with a new set of studies that focused on the firms' characteristics that affect the relationship between firms' position in a network of relationships and their performance. Accordingly they found that some brokerage positions can either substitute or complement some firms' characteristics in influencing firms performance (Shipilov 2009).

Another possible explanation for our result could be related to the typology of the innovation involved. For example, some papers focusing on the role of absorptive capacity for open innovation show that a high level of absorptive capacity (concerning previous experience) could make it difficult to switch to new technological approaches 
(King and Lakhani 2011), and that the benefit of being open could be lower for firms with high R\&D spending (Barge-Gil 2010). This is in line with the idea of the dominant logic of the firm that could be an obstacle to major changes in its knowledge structure when innovation is required (Prahalad and Bettis 1986). Even if this explanation could be attractive, it appears to us less coherent with the characteristics of the innovations in our cluster, which is more focused on incremental innovations.

A last explanation is related to the way absorptive capacity was measured. Many researchers have measured absorptive capacity as a one-dimensional construct, often using a firm's R\&D spending intensity as a proxy for this construct. This was our choice too. This measure has received some criticism (Flatten et al. 2011) and other measures have been suggested as more useful to address the capability to absorb suppliers' and competitors' knowledge (manufacturing capacity; Bogers and Lhuillery 2011), and to deal with heterogeneous information (scope of experience; Shipilov 2009). Particularly this last set of measures could capture the support that absorptive capacity provides to innovation anytime the mediated groups are more heterogeneous. The need for the broker to be familiar with both groups makes broker's function more demanding, transcoding and transferring knowledge more difficult, finding analogies and combining knowledge even more challenging.

Our paper contributes to the cluster literature by taking into consideration different brokerage roles (besides gatekeeper) and focusing on brokers accessing knowledge already flowing in the cluster. It recognizes the importance of inter-activity relationships performed by different subgroups of firms. The brokerage position between these activities could become relevant for the innovative performance of the firms. Our paper showed in fact that it is worthy to distinguish the brokerage role played 
by each firm among different activities as it could significantly impact its innovative capability.

At the same time our results sustain the idea that internal unevenly distribution of knowledge in clusters and its relations with innovation could be ascribed to different brokerage roles played by individual firms, on their absorptive capacity and, at least for liaison role, on the moderating role of the same absorptive capacity.

With reference to the social network theory our findings suggest a relevant explanatory capacity of a firm's brokerage position in networks on its innovative performance. In this sense, our findings coincide with those highlighting the importance of external resources available to the firm depending on its networks position (McEvily and Marcus 2005; Gulati, Nohria, and Zaheer 2000; Gulati 1999). Over the last few years, network analysis has made significant contributions to the understanding of the factors involved in firm performance. However, a combinative perspective that includes firm-level factors such as absorptive capacity and factors related to the network is rarely offered (Zaheer and Bell 2005). Our results concerning the moderating effect of absorptive capacity on the relation between the liaison role and the innovation performance of the broker is a further contribution to this more recent literature.

Our research contributes to the more recent literature on the role of agency in networks (Dhanaraj and Parkhe 2006; Zaheer and Soda 2009; Vanhaverbeke et al. 2009; Van Burg, Berends, and Raaij 2014). A recent qualitative study of innovation projects showed how the evolution in the exchange of knowledge in suppliers-buyers dyads impact on knowledge diffusion in networks, by focusing on firms deliberate choices (Lipparini, Lorenzoni, and Ferriani 2014). By focusing on actors behaviors in a local network we investigate how actors try to create value through it by enacting their relationships in different flows of knowledge transfer. Our study shows that firms 
belonging to the same local cluster can engage in knowledge transfer developing different brokerage roles, with different intensity, and with different implications in term of innovative capacity.

Finally, findings from our research have a number of implications at the individual firm level. Basically, firms must be able to select the most appropriate brokerage role to enhance their innovation capabilities and reduce the risk of spillover, with a conscious selection of sources, directions, content, and quality of the intermediary knowledge. Furthermore, our results concerning the substitution role of liaison activities suggest that, even if absorptive capacity has always a positive impact on innovation, firms with lower absorptive capacity can accelerate their learning process through a high liaison activity with relevant partners, which could be very attractive wherever costs of $R \& D$ is particularly high.

\section{Limitations and future research}

Our study obviously presents some limitations, which can be understood as potential directions for future research. We considered a specific local context, where innovation activities and relationships of any nature are intense and concentrated, while in other contexts they may be different. On the other hand, research using inter-firm networks is still constrained by the limitations of considering the firm at a single level. By nature, social relationships take place between individuals, and many categories of them can be distinguished. For instance, friendship networks between individuals across firms might also be significant conduits for the transfer of information and knowledge, particularly when it is tacit.

Another specific limitation refers to the measure of the absorptive capacity. As stated by Prahalad and Bettis (1986), the amount of R\&D spending does not capture the 
quality of know-how. As addressed in previous paragraphs, other measures of absorptive capacity could be used and assessed in the specific innovation context.

The negative interactive effect of absorptive capacity on the relationship between liaison role and innovative performance of cluster firms and the suggested substitution effect between brokerage and R\&D efforts seems particularly challenging and deserves further research. Particularly interesting could be to address further contingency factors such as heterogeneity of absorptive capacity and external openness.

Finally, as a further development of this research, a more complete study should include the analysis of brokerage activities involving firms located outside the cluster. Accordingly, other directions of research could be to explore in depth the conditions that explain the distinctive purposes and consequences of each brokerage role and their combination. 


\section{References}

Ács, Zoltán J., and David B. Audretsch. 1991. innovation and technological change: an overview. In Innovation and technological change: an international comparison, edited by Z. J. acs and D. B. Audretsch. Ann Arbor, MI: University of Michigan Press.

Adler, Paul S., and Seok-Woo Kwon. 2002. Social Capital: Prospects for a New Concept. Academy of Management Review 27 (1):17-40.

Arikan, AT, and Melissa A Schilling. 2011. Structure and governance in industrial districts: implications for competitive advantage. Journal of Management Studies 48 (4):772-803.

Autio, E., Harry J Sapienza, and James G. Almeida. 2000. Effects of age at entry, knowledge intensity, and imitability on international growth. Academy of Management Journal 43 (5):909924.

Barge-Gil, Andrés. 2010. Open, semi-open and closed innovators: towards an explanation of degree of openness. Industry and Innovation 17 (6):577-607.

Barney, J. B. 1991. Firm Resources and Sustained Competitive Advantage. Journal of Management 17 (1):99.

Bathelt, H., A. Malmberg, and P. Maskell. 2004. Clusters and knowledge: local buzz, global pipelines and the process of knowledge creation. Progress in Human Geography 28:31-56.

Becker, M.H. 1970. Sociometric location and innovativeness: Reformulation and extension of the diffusion model. American Sociological Review 35 (2):267-282.

Boari, C., and Andrea Lipparini. 1999. Networks within industrial districts: Organising knowledge creation and transfer by means of moderate hierarchies. Journal of Management and Governance 3 (4):339-360.

Boari, C., and Federico Riboldazzi. 2014. How knowledge brokers emerge and evolve: The role of actors' behaviour. Research Policy 43 (4):683-695.

Bogers, Marcel, and Stephane Lhuillery. 2011. A functional perspective on learning and innovation: Investigating the organization of absorptive capacity. Industry and Innovation 18 (6):581-610. 
Boix, R., and V. Galletto. 2006. El nuevo mapa de los distritos industriales de España y su comparación con Italia y el Reino Unido: Documento de trabajo 06.04. Departament d'Economia Aplicada. Universitat Autònoma de Barcelona.

Borgatti, Stephen P., MG. Everett, and LC. Freeman. 2002. Ucinet for Windows: Software for Social Network Analysis. Harvard: Analytic Technologies.

Borgatti, Stephen P., Ajay Mehra, Daniel J. Brass, and Giuseppe Labianca. 2009. Network Analysis in the Social Sciences. Science 323 (5916):892-895.

Boschma, R.A., and A.L.J. Ter Wal. 2007. Knowledge networks and innovative performance in an industrial district. Industry and Innovation 14 (2):177-199.

Bouty, I. 2000. Interpersonal and interaction influences on informal resource exchanges between R\&D researchers across organizational boundaries. Academy of Management Journal 43 (1):50-66.

Branston, J.R., L. Rubini, R. Sugden, and J.R. Wilson. 2005. Healthy governance: economic policy and the Health Industry Model. In Promoting High-Tech Industries. Can Growth Lead the Way, edited by M. R. Di Tommaso and S. O. Schweitzer. Cheltenham: Edward Elgar.

Breschi, S., and F. Lissoni. 2001. Knowledge spillovers and local innovation systems: a critical survey. Industrial and Corporate Change 10 (4):975-1005.

Brusco, S. 1982. The Emilian Model: productive decentralisation and social integration. Cambridge Journal of Economics 6:167-184.

Burt, R. S. 1992. Structural holes. Cambridge: Harvard University Press.

. 2004. Brokerage and Closure. Oxford: Oxford University Press.

Camuffo, Arnaldo. 2003. Transforming industrial districts: large firms and small business networks in the Italian eyewear industry. Industry and Innovation 10 (4):377-401.

Cohen, Jacob, Patricia Cohen, Stephen G West, and Leona S Aiken. 1983. Applied multiple regression/correlation analysis for the behavioral sciences. Hillsdale, NJ: L. Erlbaum Associates

Cohen, W.M., and D.A. Levinthal. 1990. Absorptive capacity: A new perspective on learning and innovation. Administrative Science Quarterly 35 (1):128-152.

1994. Fortune favors the prepared firm. Management Science 40 (2):227-251. 
Cooke, P. 2002. Knowledge economies: Clusters, learning and cooperative advantage. London: Routledge.

Dhanaraj, Charles, and Arvind Parkhe. 2006. Orchestrating innovation networks. Academy of Management Review 31 (3):659-669.

Dyer, Jeffrey, and Kentaro Nobeoka. 2000. Creating and managing a high performance knowledge-sharing network: the Toyota case. Strategic Management Journal 21 (Special Issue 3):345-367.

Engelen, Andreas, and Malte Brettel. 2012. A coalitional perspective on the role of the R\&D department within the organization. Journal of Product Innovation Management 29 (3):489505.

Flatten, Tessa C, Andreas Engelen, Shaker A Zahra, and Malte Brettel. 2011. A measure of absorptive capacity: Scale development and validation. European Management Journal 29 (2):98-116.

Galunic, C., and S. Rodan. 1998. Resource recombinations in the firm: knowledge structures and the potential for Schumpeterian innovation. Strategic Management Journal 19 (12):11931201.

Giner, J. M., and M. J. Santa María. 2002. Territorial systems of small firms in Spain: an analysis of productive and organizational characteristics in industrial districts. Entrepreneurship \& Regional Development 14:211-228

Giuliani, E. 2007. The selective nature of knowledge networks in clusters: evidence from the wine industry. Journal of Economic Geography 7:139-168.

- 2011. Role of technological gatekeepers in the growth of industrial clusters: Evidence from chile. Regional Studies 45 (10):1329-1348.

2013. Clusters, networks and firms' product success. An empirical study. Management Decision 51 (6).

Giuliani, E., and M. Bell. 2005. The micro-determinants of meso-level learning and innovation: evidence from a Chilean wine cluster. Research Policy 34:47-68.

Gould, Roger V., and Roberto M. Fernandez. 1989. Structures of Mediation: A Formal Approach to Brokerage in Transaction Networks. Sociological Methodology 19:89-126. 
Graf, Holger. 2011. Gatekeepers in regional networks of innovators. Cambridge Journal of Economics 35 (1):173.

Graf, Holger, and Jens J Kruger. 2011. The performance of gatekeepers in innovator networks. Industry and Innovation 18 (1):69-88.

Gulati, R. 1999. Network location and learning: The influence of network resources and firm capabilities on alliance formation. Strategic Management Journal 20 (5):397-420.

Gulati, R., N. Nohria, and A. Zaheer. 2000. Strategic networks. Strategic Management Journal $21(3): 203-215$.

Hair, Joseph F, Rolph E Anderson, RL Tatham, and WC Black. 2006. Multivariate data analysis. Upper Saddel River, NJ: Prentice Hall.

Hanneman, R.A., and M. Riddle. 2001. Social Network Analysis. Place Published: University of California, Riverside (accessed.

Hargadon, A.B. 1998. Firms as knowledge brokers: Lessons in pursuing continuous innovation. California Management Review 40 (3):209-227.

Hargadon, A.B., and R.I. Sutton. 1997. Technology brokering and innovation in a product development firm. Administrative Science Quarterly 42 (4):716-749.

Hervas-Oliver, J.L. 2004. Heterogeneidad Estratégica en un Cluster. Evidencia Empírica de la Identificación de Grupos Estratégicos a través de la cadena de valor y su impacto en la performance en el sector industrial cerámico. Unpublished Doctoral Thesis, Polytechnic University of Valencia, Valencia.

King, Andrew, and Karim Lakhani. 2011. The contingent effect of absorptive capacity: An open innovation analysis. Harvard Business School Technology \& Operations Mgt. Unit Working Paper (11-102).

Lavie, Dovev. 2006. The competitive advantage of interconnected firms: An extension of the resource-based view. Academy of management review 31 (3):638-658.

Lazerson, M. H., and G. Lorenzoni. 1999. The firms that feed industrial districts: A return to the italian source. Industrial and Corporate Change 8:235-266. 
Li, Wan, Rajaram Veliyath, and Justin Tan. 2013. Network Characteristics and Firm Performance: An Examination of the Relationships in the Context of a Cluster. Journal of Small Business Management 51 (1):1-22.

Lipparini, A., Gianni Lorenzoni, and Simone Ferriani. 2014. From core to periphery and back: A study on the deliberate shaping of knowledge flows in interfirm dyads and networks. Strategic Management Journal 35 (4):578-595.

Lissoni, F. 2001. Knowledge codification and the geography of innovation: the case of Brescia mechanical cluster. Research Policy 30 (9):1479-1500.

Lorenzoni, G., and A. Lipparini. 1999. The leveraging of interfirm relationships as a distinctive organizational capability: A longitudinal study. Strategic Management Journal 20 (4):317-338.

Malipiero, A., F. Munari, and M. Sobrero. 2005. Focal firms as technological gatekeepers within industrial districts: evidence from the packaging machinery industry. Paper read at Contribución presentada en la 2005 DRUID Winter Conference, Skorping (Dinamarca), 2005.

Marsden, Peter V. 1982. Brokerage Behavior in Restricted Exchange Networks. In Social Structure and Network Analysis, edited by P. V. Marsden and L. Nan. Beverly Hills: Sage.

Marshall, A. 1925. Principles of economics (1890). London: Macmillan.

Maskell, P., and A. Malmberg. 1999. Localized learning and industrial competitiveness. Cambridge Journal of Economics 23:167-185.

McEvily, B., and A. Marcus. 2005. Embedded ties and the acquisition of competitive capabilities. Strategic Management Journal 26 (11):1033-1055.

McEvily, B., and A. Zaheer. 1999. Bridging ties: A source of firm heterogeneity in competitive capabilities. Strategic Management Journal 20 (12):1133-1156.

Molina-Morales, Francesc Xavier. 2002. Industrial districts and innovation: the case of the Spanish ceramic tiles industry. Entrepreneurship \& Regional Development 14 (4):317-335.

2005. The territorial agglomerations of firms: A social capital perspective from the Spanish tile industry. Growth and Change 36 (1):74-99.

Morrison, A. 2008. 'Gatekeepers of knowledge' within industrial districts: who they are, how they interact. Regional Studies 42 (6):817-835. 
Morrison, A., and R. Rabellotti. 2009. Knowledge and information networks in an Italian wine cluster. European Planning Studies 17 (7):983-1006.

Mowery, David C, Joanne E Oxley, and Brian S Silverman. 1996. Strategic alliances and interfirm knowledge transfer. Strategic Management Journal 17:77-91.

Munari, F., M. Sobrero, and A. Malipiero. 2012. Absorptive capacity and localized spillovers: focal firms as technological gatekeepers in industrial districts. Industrial and Corporate Change $21(2): 429-462$.

Obstfeld, David. 2005. Social networks, the tertius iungens orientation, and involvement in innovation. Administrative Science Quarterly 50 (1):100-130.

Owen-Smith, Jason, and Walter W Powell. 2004. Knowledge networks as channels and conduits: The effects of spillovers in the Boston biotechnology community. Organization Science 15 (1):5-21.

Parrilli, Mario Davide, and S. Sacchetti. 2008. Linking learning with governance in networks and clusters: key issues for analysis and policy. Entrepreneurship \& Regional Development 20 (4):387-408.

Piore, M., and C. Sabel. 1984. The second industrial divide: Possibilities for prosperity. New York: Basic Books.

Porter, Michael E. 1990. The competitive advantage of nations. New York: Free Press. 1998. Clusters and the New Economics of Competition. Harvard Business Review December:77-90.

Prahalad, C. K., and Richard A Bettis. 1986. The dominant logic: A new linkage between diversity and performance. Strategic Management Journal 7 (6):485-501.

Rosenkopf, Lori, and Paul Almeida. 2003. Overcoming local search through alliances and mobility. Management Science 49 (6):751-766.

Russo, M. 1985. Technical change and the industrial district: the role of interfirm relations in the growth and transformation of ceramic tile production in Italy. Research Policy 14 (6):329343.

Sammarra, A., and L. Biggiero. 2008. Heterogeneity and Specificity of Inter-Firm Knowledge Flows in Innovation Networks. Journal of Management Studies 45 (4):800-829. 
Saxenian, A. 1991. The origin and dynamics of production networks in Silicon Valley. Research Policy 20:423-437.

Shi, Weilei, Livia Markoczy, and Gregory G Dess. 2009. The role of middle management in the strategy process: group affiliation, structural holes, and Tertius Iungens. Journal of Management 35 (6):1453-1480.

Shipilov, A.V. 2009. Firm scope experience, historic multimarket contact with partners, centrality, and the relationship between structural holes and performance. Organization Science 20 (1):85-106.

Spencer, Jennifier W. 2003. Global gatekeeping, representation, and network structure: a longitudinal analysis of regional and global knowledge-diffusion networks. Journal of International Business Studies 34 (5):428-442.

Stork, Diana, and William D. Richards. 1992. Nonrespondents in communication network studies: problems and possibilities. Group \& Organization Management 17 (2):193-209.

Tallman, S., M. Jenkins, N. Henry, and S. Pinch. 2004. Knowledge, clusters, and competitive advantage. The Academy of Management Review 29:258-271.

Tomlinson, Philip R. 2010. Co-operative ties and innovation: Some new evidence for UK manufacturing. Research Policy 39 (6):762-775.

Tsai, W. 2001. Knowledge transfer in intraorganizational networks: effects of network position and absorptive capacity on business unit innovation and performance. Academy of Management Journal 44 (5):996-1004.

Tsai, W., and S. Ghoshal. 1998. Social capital and value creation: The role of intrafirm networks. Academy of Management Journal 41 (4):464-478.

Uzzi, B., and J. Spiro. 2005. Collaboration and Creativity: The Small World Problem. American Journal of Sociology 111 (2):447-504.

Van Burg, Elco, Hans Berends, and Erik M. Raaij. 2014. Framing and interorganizational knowledge transfer: A process study of collaborative innovation in the aircraft industry. Journal of Management Studies 51 (3):349-378.

Vanhaverbeke, Wim, Victor Gilsing, Bonnie Beerkens, and Geert Duysters. 2009. The Role of Alliance Network Redundancy in the Creation of Core and Non-core Technologies. Journal of Management Studies 46 (2):215-244. 
Von Hippel, E. 1977. Has a customer already developed your next product? Sloan Management Review 18 (2):63-74.

Whittington, Kjersten Bunker, Jason Owen-Smith, and Walter W. Powell. 2009. Networks, propinquity, and innovation in knowledge-intensive industries. Administrative Science Quarterly 54 (1):90-122.

Wink, Rudiger. 2008. Integrative technologies and knowledge gatekeepers: Bridging the gap between epistemic communities in the case of stem cell science. International journal of learning and change 3 (1):57-74.

Ybarra, J. A. 1991. Determinación cuantitativa de distritos industriales: la experiencia del País Valenciano. Estudios Territoriales 37:53-67.

Yli-Renko, Helena, Erkko Autio, and Harry J Sapienza. 2001. Social capital, knowledge acquisition, and knowledge exploitation in young technology-based firms. Strategic Management Journal 22 (6-7):587-613.

Zaheer, Akbar, and G.G. Bell. 2005. Benefiting from network position: firm capabilities, structural holes, and performance. Strategic Management Journal 26 (9):809-825.

Zaheer, Akbar, and Giuseppe Soda. 2009. Network evolution: The origins of structural holes. Administrative Science Quarterly 54 (1):1-31. 
FIGURE 1: TYPOLOGY OF BROKERAGE ROLES BASED ON GOULD AND FERNANDEZ (1989)

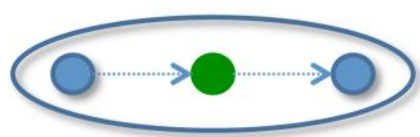

Coordinator

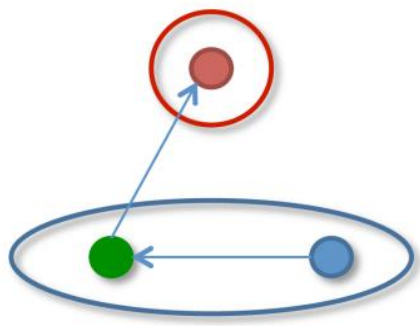

Representative

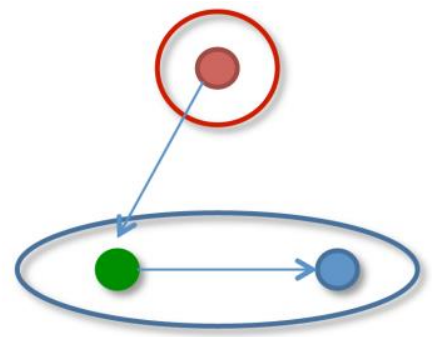

Gatekeeper

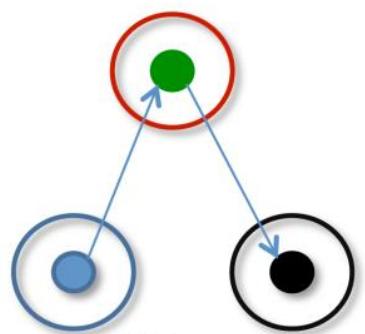

Liaison
Broker

$\longrightarrow$ Information Flow
Activity

(Value System)

FIGURE 2. INNOVATION AND INTERACTIVE EFFECT OF THE LIAISON ACTIVITIES AND ABSORPTIVE CAPACITY

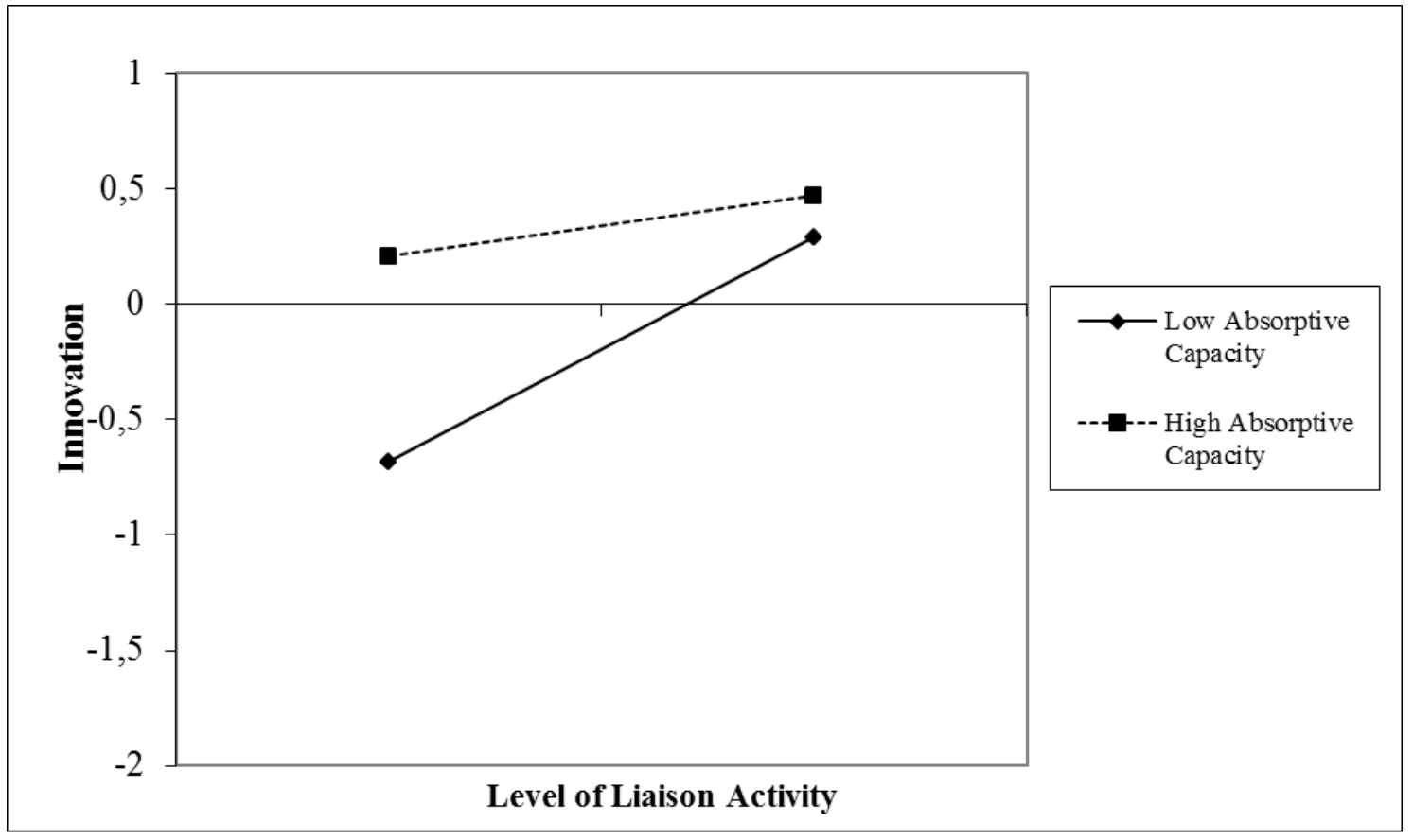


TABLE I. RESPONDENTS’ PROFILE

\begin{tabular}{|lcc|}
\hline Position & Number of respondents & $\%$ \\
\hline General Manager & 61 & $36 \%$ \\
\hline R\&D director & 48 & $29 \%$ \\
\hline Chief technical officer & 41 & $25 \%$ \\
\hline Other staff members & 16 & $10 \%$ \\
\hline TOTAL & 166 & $100 \%$ \\
\hline
\end{tabular}

TABLE 2. SAMPLE DISTRIBUTION BY CLUSTER PRODUCTIVE ACTIVITIES

\begin{tabular}{|lcc|}
\hline Activities & Number of companies & $\mathbf{\%}$ \\
\hline Ceramic wall and floor tile producers & 83 & 50.0 \\
\hline Glaze and frit producers & 21 & 12.7 \\
\hline Machinery and equipment producers & 36 & 21.7 \\
\hline Special and decorative ceramic pieces producers & 16 & 9.6 \\
\hline Atomized clay producers & 6 & 3.6 \\
\hline Chemical additives producers & 4 & 2.4 \\
\hline Total & 166 & 100 \\
\hline
\end{tabular}


TABLE 3. CORRELATION MATRIX

\begin{tabular}{|c|c|c|c|c|c|c|c|c|c|c|c|c|c|}
\hline & $\begin{array}{c}\text { Descriptive } \\
\text { Statistics MEAN } \\
\text { (SD) }\end{array}$ & Min & Max & $\begin{array}{l}\text { Innovative } \\
\text { Performance }\end{array}$ & Size & $\begin{array}{c}\text { External } \\
\text { Openness }\end{array}$ & $\begin{array}{l}\text { Age of R\&D } \\
\text { Department }\end{array}$ & Age of firm & Coordinator & Gatekeeper & Representative & Liaison & $\begin{array}{c}\text { Absorptive } \\
\text { Capacity }\end{array}$ \\
\hline $\begin{array}{l}\text { Innovative } \\
\text { Performance }\end{array}$ & $0.000(1.000)$ & -1.735 & 1.139 & 1 & & & & & & & & & \\
\hline Size & $0.000(1.000)$ & -.720 & 1.000 &, $277 * * *$ & 1 & & & & & & & & \\
\hline $\begin{array}{l}\text { External } \\
\text { Openness }\end{array}$ & $1.000(2.024)$ & 0.000 & 11.000 &, $248^{* * *}$ &, $471 * * *$ & 1 & & & & & & & \\
\hline $\begin{array}{l}\text { Age of R\&D } \\
\text { Department }\end{array}$ & $10.386(9.255)$ & 0.000 & 49.000 &, $368^{* * *}$ &, $286^{* * *}$ &, $298 * * *$ & 1 & & & & & & \\
\hline Age of the frm & $26.988(13.643)$ & 3.000 & 63.000 &, $108^{*}$ &, $269^{* * *}$ &, $109^{*}$ &, $246 * * *$ & 1 & & & & & \\
\hline Coordinator & $0.225(0.851)$ & 0.000 & 7.420 &, $110^{*}$ &, 039 &, 078 &,- 032 &,- 001 & 1 & & & & \\
\hline Gatekeeper & $0.348(0.638)$ & 0.000 & 5.400 &, $101^{*}$ &, $122^{*}$ & ,037 &, 021 & ,007 &, $208 * * *$ & 1 & & & \\
\hline Representative & $0.358(0.516)$ & 0.000 & 2.700 &, $121^{*}$ &, $126^{*}$ &, $120^{*}$ &, $130 * *$ &, $119 *$ &, $273^{* * *}$ &, $525 * * *$ & 1 & & \\
\hline Liaison & $0.889(0.839)$ & 0.000 & 3.230 &, $366^{* * *}$ &, $216^{* * *}$ &, $140 * *$ &, $145^{* *}$ & ,036 &,$- 186^{* * * *}$ &,$- 101^{*}$ & -0.028 & 1 & \\
\hline $\begin{array}{l}\text { Absorptive } \\
\text { Capacity }\end{array}$ & $2.020(1.425)$ & 0.000 & 6.000 &, $255^{* * *}$ & ,026 &,$- 162 * *$ & 021 &,- 066 & 056 &, $169^{* *}$ & $0.133^{* *}$ & 0.006 & 1 \\
\hline
\end{tabular}

$\mathrm{N}=166 ; * * * \mathrm{p}<0.01 ; * * \mathrm{p}<0.05 ; * \mathrm{p}<0$. 
TABLE 4. MODELS OF THE INTERACTION EFFECTS

\begin{tabular}{|c|c|c|c|c|}
\hline & Model 1 & Model 2 & Model 3 & Model 4 \\
\hline Constant & $0.000(0.071)$ & $0.000(0.067)$ & $0.000(0.064)$ & $0.071(0.067)$ \\
\hline Size & $0.154(0.084)^{*}$ & $0.076(0.081)$ & $0.047(0.078)$ & $0.043(0.079)$ \\
\hline External openness & $0.087(0.083)$ & $0.066(0.078)$ & $0.129(0.077)^{*}$ & $0.182(0.079)^{* *}$ \\
\hline Age of $R \& D$ & $0.303(0.078)^{* * *}$ & $0.283(0.074)^{* * *}$ & $0.266(0.071)^{* * *}$ & $0.217(0.072)^{* * *}$ \\
\hline \multicolumn{5}{|l|}{ Department } \\
\hline Age of firm & $-0.017(0.076)$ & $0.000(0.072)$ & $0.025(0.069)$ & $0.004(0.068)$ \\
\hline Coordinator & & $0.159(0.072)^{* *}$ & $0.151(0.069)^{* *}$ & $0.160(0.078)^{* *}$ \\
\hline Gatekeeper & & $0.092(0.080)$ & $0.063(0.078)$ & $0.028(0.078)$ \\
\hline Representative & & $-0.016(0.082)$ & $-0.037(0.079)$ & $-0.040(0.083)$ \\
\hline Liaison & & $0.338(0.071)^{* * *}$ & $0.331(0.068)^{* * * *}$ & $0.309(0.068)^{* * *}$ \\
\hline Absorptive Capacity & & & $0.255(0.067)^{* * *}$ & $0.267(0.067)^{* * *}$ \\
\hline Absorptive Capacity & & & & $-0.003(0.091)$ \\
\hline \multicolumn{5}{|l|}{$\times$ Coordinator } \\
\hline Absorptive Capacity & & & & $-0.165(0.107)$ \\
\hline \multicolumn{5}{|l|}{$\times$ Gatekeeper } \\
\hline Absorptive Capacity & & & & $-0.039(0.084)$ \\
\hline \multicolumn{5}{|l|}{$\times$ Representative } \\
\hline Absorptive Capacity & & & & $-0.178(0.063)^{* * *}$ \\
\hline \multicolumn{5}{|l|}{$\times$ Liaison } \\
\hline$F$ & $8.460 * * *$ & $6.464 * * *$ & $14.282 * * *$ & $2.814 * * *$ \\
\hline$R^{2}$ & 0.174 & 0.291 & 0.350 & 0.395 \\
\hline$R^{2}$ adjusted & 0.153 & 0.254 & 0.313 & 0.343 \\
\hline Increase of $R^{2}$ & $0.174 * * *$ & $0.117 * * *$ & $0.060 * * *$ & $0.045^{* * *}$ \\
\hline
\end{tabular}

$\mathrm{N}=166 ; * * * \mathrm{p}<0.01 ; * * \mathrm{p}<0.05 ; * \mathrm{p}<0.1$. Non-standard coefficients (errors in brackets) 


\section{APPENDIX 1. ITEMS FOR INNOVATION}

Over the last three years, has your company introduced any of the following innovations?

\begin{tabular}{|l|}
\hline Product innovations: \\
\hline 1. - New or improved goods and services already available to competitors \\
\hline 2. - New or improved goods and services before competitors \\
\hline Process innovations: \\
\hline 3. - New or improved goods and services production methods \\
\hline 4. - New or improved logistic systems or delivery methods or distribution channels \\
\hline 5. - Process-supporting activities \\
\hline
\end{tabular}

\section{Notes}

\footnotetext{
${ }^{1}$ In the conceptualization of the types of broker we followed Gould and Fernandez (1989). However, we considered only four types of broker since, for the purposes of this paper, we found no relevance for the cosmopolitan or itinerant broker, which defines the case when the two principals belong to the same subgroup while the intermediary belongs to a different group.

2 This database includes financial analyses of more than 1,080,000 Spanish firms and 320,000 Portuguese companies with annual reports dating up to 10 years ago. Prepared by Bureau van Dijk, data are obtained from official sources, mercantile registries, BORME (the Mercantile Registry's official gazette), the press, etc..
} 